\title{
Tetrachloro-1,4-benzoquinone induces apoptosis of mouse embryonic stem cells
}

\section{Cuiping Li, Fengbang Wang, Hailin Wang*}

State Key Laboratory of Environmental Chemistry and Ecotoxicology, Research Center for Eco-Environmental Sciences, Chinese Academy of Sciences, Beijing 100085, China. E-mail: licuiping198585@126.com

\section{A R T I C L E I N F O}

Article history:

Received 19 March 2016

Revised 19 April 2016

Accepted 2 May 2016

Available online 16 July 2016

Keywords:

Tetrachloro-1,4-benzoquinone

Ten-eleven translocation

5-Hydroxymethylcytosine

Early apoptosis

Late apoptosis

\begin{abstract}
A B S T R A C T
Pentachlorophenol (PCP) is a widespread, persistent environmental contaminant, and it is enzymatically activated to form a reactive metabolite, tetrachloro-1,4-benzoquinone (TCBQ). To our knowledge, there is no information about TCBQ toxicity on embryonic stem cells. Here, we demonstrated that TCBQ induced significantly apoptosis of mouse embryonic stem cells in a concentration-dependent manner. We also showed that TCBQ elevated genomic 5-hydroxymethylcytosine $(5 \mathrm{hmC})$ by affecting ten-eleven translocation (Tet) dioxygenases in mouse embryonic stem cells. We further investigated whether Tet dioxygenases were implicated in TCBQ-induced apoptosis. By depleting all three dioxygenases (Tet1-3), we found that Tet dioxygenases slightly inhibited both early and late apoptosis induced by TCBQ at a low concentration $(30 \mu \mathrm{mol} / \mathrm{L})$. Meanwhile, treated by TCBQ at higher concentrations (40 and $50 \mu \mathrm{mol} / \mathrm{L}$ ), the total percentage of apoptotic cells was not affected by Tet dioxygenases. However, Tet dioxygenases tended to arrest mouse ES cells to be at early apoptotic stage and to reduce the cells to enter later apoptotic stage. These results indicate that Tet dioxygenases play a role in shaping TCBQ-induced apoptosis in mouse embryonic stem cells. Our study provides new insights into the toxicology of PCP and its reactive metabolite TCBQ.
\end{abstract}

(C) 2016 The Research Center for Eco-Environmental Sciences, Chinese Academy of Sciences.

Published by Elsevier B.V.

\section{Introduction}

Pentachlorophenol (PCP) is a chlorinated phenolic compound that has been widely used as a critical ingredient in biocides and wood preservatives (Hattemer-Frey and Travis, 1989). In China, the annual national production of PCP reached approximately 3000 tons in 2003, but no recent data were reported (Zheng et al., 2012). Among them, approximately $60 \%$ of PCP was applied as a molluscicide to prevent snail-borne schistosomiasis, whereas the remaining $40 \%$ was used in wood preservatives and for other purposes (Zheng et al., 2012). Because of its widespread usage and persistence, PCP is ubiquitously distributed in environment. Indeed, it has been detected in surface water, rainwater, drinking water, soil, food, human urine, milk, serum and adipose tissues in people who do not physically contact PCP (Zhu and Shan, 2009; Angelucci and Tomei, 2015). PCP can result in many adverse effects on health and the eco-environment; it is identified as a group 2B carcinogen (possible human carcinogen) by the International Agency for Research on Cancer (IARC) and a priority pollutant by U.S. Environmental Protection Agency (EPA) (IARC, 1991).

The genotoxicity of PCP is mainly attributed to its reactive metabolites: tetrachlorohydroquinone (TCHQ) and tetrachloro-1,

\footnotetext{
* Corresponding author. E-mail: hlwang@rcees.ac.cn (Hailin Wang).
} 
4-benzoquinone (TCBQ) (Zhu and Shan, 2009). Dependent on the metabolic activation of cytochrome $\mathrm{P} 450$ or monooxygenases, PCP is transformed to the reactive metabolite TCBQ which readily reacts with nucleophiles, such as protein and DNA (Hu et al., 2015). Previous studies have suggested that TCBQ can induce oxidative DNA damage, DNA adducts and DNA single-strand breaks in vivo and in vitro system, indicating TCBQ-induced genotoxicity (Lin et al., 2001; Zhu and Shan, 2009; Yin et al., 2013a, 2013b). However, its toxicity has not been fully evaluated, and little is known about its stem cell toxicity.

Stem cell toxicology is a powerful tool to replace in vivo animal experiments or in vitro primary cell tests because stem cells can be easily obtained and have the capability of unlimited proliferation (Faiola et al., 2015; Li et al., 2015). Because of their pluripotency, embryonic stem cells can differentiate into all cell types of adult organisms; thus, we can test the potential effects of pollutants on various types of somatic cells, particularly cells that are difficult to be obtained from animals and humans. Therefore, the use of embryonic stem cells decreases the costs, time and labor of experiments (Faiola et al., 2015; Yin et al., 2015). Essentially, embryonic stem cells are more sensitive than somatic cells to various toxic pollutants and can be used in developmental toxicity assays (Faiola et al., 2015). These unique characteristics make embryonic stem cells ideal for toxicity assays of environmental pollutants (Faiola et al., 2015; Yin et al., 2015). To this end, it is interesting to know the toxicology properties of TCBQ on embryonic stem cells.

Our group has demonstrated that TCBQ can promote the conversion of 5-methylcytosine $(5 \mathrm{mC})$ to 5-hydroxymethyl cytosine $(5 \mathrm{hmC})$ by stimulating Tet oxidation activity in mammalian cells (Zhao et al., 2014). Tet family proteins are Fe (II)/ $\alpha$-ketoglutarate $(\alpha-K G)$-dependent dioxygenases. The treatment of TCBQ results in the up-regulation of the ferritin light chain (FTL), which is positively correlated with labile iron, and the increased concentration of labile iron as an indispensable cofactor enhances Tet oxidation activity and promotes the formation of $5 \mathrm{hmC}$ (Zhao et al., 2014). Here, we tested the effects of a series of concentrations of TCBQ on $5 \mathrm{hmC}$ in mouse embryonic stem (ES) cells and evaluated the TCBQ-induced toxicity by monitoring apoptosis in the mouse ES cells. Based on the TCBQ-stimulated generation of $5 \mathrm{hmC}$ in a Tet-dependent manner, we further investigated the relevance of Tet dioxygenases to apoptosis caused by TCBQ.

\section{Materials and methods}

\subsection{Materials}

DMEM medium with high glucose, trypsin and embryonic stem cell FBS were purchased from Hyclone (Thermo Fisher Scientific, Inc., USA). The mixture of penicillin and streptomycin was obtained from Cellgro (Corning Incorporated, USA). L-glutamine, non-essential amino acids and sodium pyruvate were obtained from Gibco (Life Technologies Corporation, USA). PD0325901 and CHIR99021 were obtained from Stemgent (USA). The leukemia inhibitory factor (LIF) was purchased from Millipore (USA). TCBQ and the Annexin V-FITC apoptosis detection kit were obtained from Sigma (USA). The apoptosis inducer kit (COO05) was purchased from Beyotime Institute of Biotechnology (Haimen, China).

\subsection{Cell culture}

Wild-type mouse embryonic stem cells (WT, 129 SvEv) and Tet1/ 2/3 triple knock-out (TKO) cells were used in the assay. These cells were kindly provided by Prof. Guoliang Xu (Shanghai Institutes for Biological Sciences, Chinese Academy of Sciences, Shanghai, China). These cells were maintained in DMEM medium, which was supplemented with $20 \%$ ES FBS, penicillin (33 IU/mL), streptomycin (33 $\mu \mathrm{g} / \mathrm{mL}$ ), $1000 \mathrm{U} / \mathrm{mL}$ leukemia inhibitory factor (LIF), $2 \mathrm{mmol} / \mathrm{L}$ L-glutamine, $0.1 \mathrm{mmol} / \mathrm{L} \quad \beta$-mercaptoethanol, $0.1 \mathrm{mmol} / \mathrm{L}$ non-essential amino acids, $1 \mathrm{mmol} / \mathrm{L}$ sodium pyruvate, $1.0 \mu \mathrm{mol} / \mathrm{L}$ PD032590 and $3.0 \mu \mathrm{mol} / \mathrm{L}$ CHIR99021. The cells were seeded in culture dishes that were pre-treated with $0.1 \%$ gelatin for $15 \mathrm{~min}$ and cultured at $37^{\circ} \mathrm{C}$ in a humidified $5 \% \mathrm{CO}_{2}$ atmosphere.

\subsection{Cell treatment using TCBQ}

For $5 \mathrm{hmC}$ and $5 \mathrm{mC}$ assay, WT mouse ES cells were seeded in culture medium for $24 \mathrm{hr}$ and then treated with 1, 10, 20, 40, $50 \mu \mathrm{mol} / \mathrm{L}$ TCBQ for $24 \mathrm{hr}$, while TKO mouse ES cells were exposed to $40 \mu \mathrm{mol} / \mathrm{L}$ TCBQ. For apoptosis analysis, both WT and TKO mouse ES cells were treated by 20, 30, 40 and $50 \mu \mathrm{mol} / \mathrm{L}$ TCBQ for $24 \mathrm{hr}$. Thereafter, the cells were collected with trypsin for further analysis. TCBQ was dissolved in dimethylsulfoxide (DMSO); thus, an equal amount of DMSO was used as the control. DMSO percentage was lower than $0.05 \%(\mathrm{~V} / \mathrm{V})$ in TCBQ-added medium.

\subsection{DNA extraction and enzymatic digestion}

Genomic DNA was extracted with a Genomic DNA Purification Kit (Promega, USA) following the manufacturer's instructions. The concentration and quality of the extracted DNA were determined using a NanoDrop 2000 (Thermo Fisher Scientific, Inc., USA) by evaluating the absorbance at 260 and $280 \mathrm{~nm}$.

For the analysis, $5 \mu \mathrm{g}$ of genomic DNA was digested into mononucleosides with $2 \mathrm{U}$ calf intestinal phosphatase, $1 \mathrm{U}$ DNase I and $0.005 \mathrm{U}$ snake venom phosphodiesterase I (New England Biolabs) at $37^{\circ} \mathrm{C}$ overnight. The digestion enzymes were removed via ultra-filtration tubes with a molecule weight cutoff of $3 \mathrm{kDa}$ (Pall Corporation, USA) by centrifuging at 12,000 $\times \mathrm{g}$ for $30 \mathrm{~min}$. The filter solution was analyzed with ultra-high performance liquid chromatography-triple quadrupole mass spectrometry (UHPLC-MS/MS) for $5 \mathrm{hmC}$ and $5 \mathrm{mC}$.

\subsection{UHPLC-MS/MS analysis of $5 \mathrm{hmC}$ and $5 \mathrm{mC}$}

The $5 \mathrm{hmC}$ and $5 \mathrm{mC}$ analysis was performed with an Agilent 1290 UHPLC system (Agilent Technologies, USA) that was coupled with an Agilent G6410B triple quadrupole mass spectrometer (Agilent Technologies, USA). The method was identical to the published method with a minor modification (Yin et al., 2013a, 2013b). In the UHPLC analysis, the Zorbax Eclipse Plus C18 column (100 mm $\times 2.1 \mathrm{~mm}, 1.8 \mu \mathrm{m}$, Agilent Technologies, USA) was used for the $5 \mathrm{hmC}$ and $5 \mathrm{mC}$ analysis. For $5 \mathrm{hmC}$, gradient elution was used: 0-3 min, 
$5.0 \% \mathrm{~B}$; 3-6 $\mathrm{min}, 15.0 \% \mathrm{~B}$; 6-10 $\mathrm{min}, 100 \% \mathrm{~B}$; and $10-15 \mathrm{~min}$, $5.0 \% \mathrm{~B}$ at a flow rate of $0.25 \mathrm{~mL} / \mathrm{min}$. Solvent A was $2.0 \mathrm{mM}$ $\mathrm{NH}_{4} \mathrm{HCO}_{3}$ aqueous solution ( $\mathrm{pH} 9.0$ ), and solvent $\mathrm{B}$ was $100 \%$ methanol. For $5 \mathrm{mC}$ and $\mathrm{C}$, the mobile phase was composed of $5.0 \%$ methanol and $95 \%$ water with $0.1 \%$ formic acid. The flow rate was $0.3 \mathrm{~mL} / \mathrm{min}$. The ESI-G6410B triple quadrupole mass spectrometer (Agilent Technologies, USA) in the multiple reaction monitoring (MRM) mode was used for the MS/MS analysis. The capillary and fragment voltages were set at +3500 and $90 \mathrm{~V}$, respectively. The transitions were monitored as follows: $\mathrm{m} / \mathrm{z} 258 \rightarrow 142$ for $5 \mathrm{hmC}$ (collision energy, $5 \mathrm{eV}), \mathrm{m} / \mathrm{z} 242 \rightarrow 126$ for $5 \mathrm{mC}(5 \mathrm{eV}), \mathrm{m} / \mathrm{z} 228 \rightarrow 112$ for $\mathrm{dC}(5 \mathrm{eV})$ and $\mathrm{m} / \mathrm{z} 268 \rightarrow 110$ for $\mathrm{dG}(5 \mathrm{eV})$. The stable isotopes $5^{\prime}$ - $\left(\right.$ methyl- $\left._{3}\right)-2^{\prime}$-deoxycytidine $\left(\left[D_{3}\right]\right) 5 \mathrm{mC}$ (Toronto Research Chemicals, Inc., Canada), 5'-(hydroxymethyl- $d_{3}$ )$2^{\prime}$-deoxycytidine $\left(\left[\mathrm{D}_{3}\right]\right) 5 \mathrm{hmC}(\mathrm{m} / \mathrm{z} 261 \rightarrow 145)$ and $\left[{ }^{15} \mathrm{~N}_{3}\right]-\mathrm{dC}$ $(\mathrm{m} / \mathrm{z} 231 \rightarrow 115)$ (Cambridge Isotope laboratories, Inc., USA) were used as internal standards for the calibration of $5 \mathrm{mC}$ and $5 \mathrm{hmC}$, respectively, and the $5 \mathrm{hmC}$ and $5 \mathrm{mC}$ concentrations were estimated based on the corresponding standard curves. Each sample was analyzed three times with an injection volume of $5 \mu \mathrm{L}$.

\subsection{Flow cytometry assay of TCBQ-induced apoptosis}

An apoptosis assay was performed with the FITC Annexin $\mathrm{V}$ apoptosis detection kit I according to the manufacturer's instructions. After $24 \mathrm{hr}$ of treatment with TCBQ, the culture medium was transferred to a centrifuge tube, and the cells were washed once with PBS and harvested by digesting with trypsin/EDTA. After collection, the cells were washed again with PBS and resuspended in $400 \mu \mathrm{L}$ of $1 \times$ binding buffer. Annexin V-FITC and propidium iodide (PI) were added to the cells and incubated for $15 \mathrm{~min}$ at RT in the dark. The control cells received an identical treatment. Wild-type mouse ES cells treated with an apoptosis inducer kit were used as positive control. Apoptosis was determined using a FACS Calibur flow cytometer, and the data were analyzed using Cell Quest software (Becton Dickinson (BD), Franklin Lakes, NJ, USA). Ten thousand cells were counted in all assays.

\subsection{Statistical analysis}

Statistical analysis was performed using the GraphPad Prism 5.0 software (GraphPad Software, Inc., USA). The statistical significance between the control and the experimental groups was evaluated using two-tailed and unpaired Student's t-test. $p$ values below 0.05 were considered significant $\left({ }^{*} p<0.05 ;{ }^{* *} p<0.01\right.$; ${ }^{* * *} p<0.001$ ). All experiments were repeated three times. The results were shown as mean $\pm \mathrm{SD}$ (standard deviation).

\section{Results and discussion}

\subsection{TCBQ stimulated a Tet-dependent an increase in genomic $5 \mathrm{hmC}$ in mouse ES cells}

DNA methylation as an important epigenetic modification plays essential roles in the regulation of gene expression,
$\mathrm{X}$-chromosome inactivation, gene imprinting, and transposable-element silencing (Bird, 2002; Deaton and Bird, 2011; Wu and Zhang, 2010; Li and Zhang, 2014). Recent studies have found that $5 \mathrm{mC}$ can be converted to $5 \mathrm{hmC}$ under the catalytic oxidation of Tet dioxygenases (Tahiliani et al., 2009; Wu and Zhang, 2011). The generated $5 \mathrm{hmC}$ can be further oxidized by Tet enzymes to form 5-formylcytosine $(5 \mathrm{fC})$ and 5 -carboxylcytosine $(5 \mathrm{caC})$, which can be removed by thymine DNA glycosylase (TDG) and revert to cytosine (C) via the base excision repair (BER) pathway (He et al., 2011; Maiti and Drohat, 2011), indicating an active DNA demethylation process.

Our previous studies suggested that the generation of $5 \mathrm{hmC}$ increases with an increasing concentration of TCBQ in somatic cells (Zhao et al., 2014). To confirm the correlation between TCBQ and $5 \mathrm{hmC}$ in mouse ES cells, we treated mouse ES cells with a series of concentrations of TCBQ. The $5 \mathrm{hmC}$ level was examined using UHPLC-MS/MS. As shown in Fig. $1 \mathrm{a}$ and $\mathrm{b}, 1 \mu \mathrm{mol} / \mathrm{L}$ of TCBQ did not statistically change the $5 \mathrm{hmC}$ content, and the $5 \mathrm{hmC}$ content after treated by $10 \mu \mathrm{mol} / \mathrm{L}$ TCBQ increased to $1.14 \times 10^{3}$ per million C compared to the DMSO control $\left(9.5 \times 10^{2}\right.$ per million C), which suggests a 1.2-fold increase. Furthermore, the $5 \mathrm{hmC}$ content increased by 1.5, 1.8, and 1.9 times when the cells were exposed to 20, 40, and $50 \mu \mathrm{mol} / \mathrm{L}$ TCBQ respectively. These data show that TCBQ causes a concentration-dependent increase of $5 \mathrm{hmC}$ in mouse ES cells. However, the $5 \mathrm{mC}$ content did not show a statistically significant change after TCBQ treatment except that $40 \mu \mathrm{mol} / \mathrm{L}$ TCBQ induced a slight increase in $5 \mathrm{mC}$ (Fig. 1c and d). The reason why elevated $5 \mathrm{hmC}$ did not result in less $5 \mathrm{mC}$ is not clear.

Tet dioxygenases are enzymatically associated with $5 \mathrm{hmC}$ formation by catalyzing oxidation of $5 \mathrm{mC}$ in genomic DNA. Therefore, tested the roles of Tet enzymes in TCBQ-stimulated production of $5 \mathrm{hmC}$ in mouse ES cells. The Tet family consists of three members, Tet1, Tet2 and Tet3, in mammalian cells (Tahiliani et al., 2009). After the triple knockout of Tet1/Tet2/ Tet3 in mouse ES cells, 5hmC was barely detectable even after a treatment with a relatively high concentration of TCBQ $(40 \mu \mathrm{mol} / \mathrm{L})$. An enlarged inset in Fig. 1b showed the $5 \mathrm{hmC}$ content in TKO mouse ES cells. The $5 \mathrm{mC}$ level was not changed by TCBQ treatment, but the deletion of Tet1/Tet2/Tet3 led to higher content in $5 \mathrm{mC}$, because Tet-knockout abolished the oxidation of $5 \mathrm{mC}$ to $5 \mathrm{hmC}$ (Fig. 1c and d). These results support that the TCBQ-stimulated generation of $5 \mathrm{hmC}$ depends on Tet dioxygenases in mouse ES cells, which is consistent with our recent report (Zhao et al., 2014). Our previous study indicates that TCBQ increases the expression of ferritin light chain (FTL) and subsequently results in a sequential increase in the amount of labile iron, oxidation activity of Tet and generation of $5 \mathrm{hmC}$ (Zhao et al., 2014).

\subsection{TCBQ induces apoptosis in mouse ES cells}

Recent studies have linked alterations in $5 \mathrm{hmC}$ to apoptosis in human skin cancer cells, and they attributed that the changes in $5 \mathrm{hmC}$ directly imply DNA demethylation and stimulate the expression of p16 and p21 genes that are associated with cell apoptosis (Lin et al., 2014). Therefore, we evaluated TCBQ-induced apoptosis in mouse ES cells. Mouse ES cells were exposed to TCBQ in the concentration range of 0 to $50 \mu \mathrm{mol} / \mathrm{L}$. An 

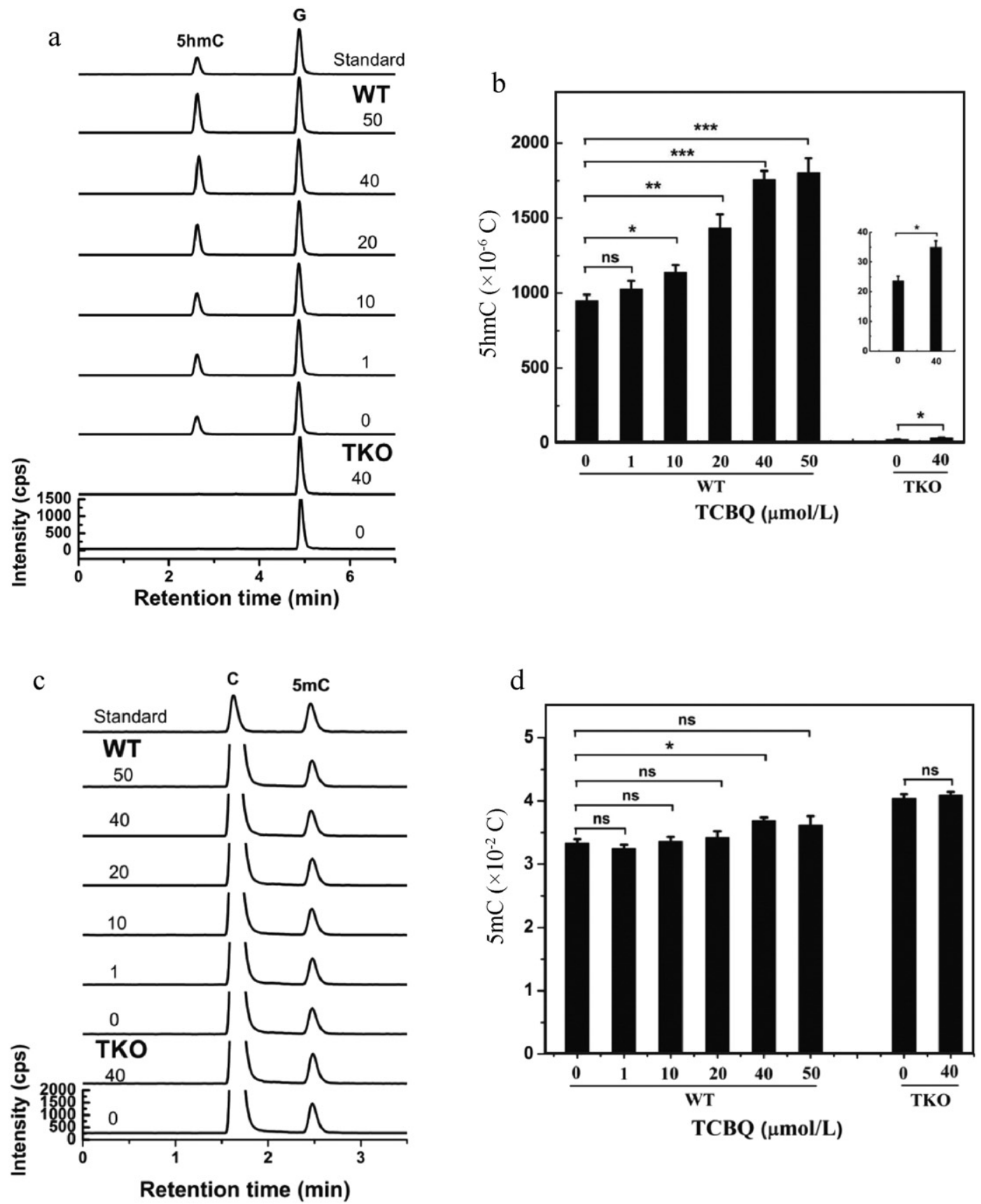

Fig. 1 - Tet-dependent generation of $5 \mathrm{hmC}$, which was stimulated by a series of TCBQ concentrations in wild-type (WT) and Tet1/Tet2/Tet3 triple-knockout (TKO) mouse embryonic stem (ES) cells. UHPLC-MS/MS analysis of $5 \mathrm{hmC} \mathrm{(a)} \mathrm{and} 5 \mathrm{mC}$ (c) of WT mouse ES cells that were treated with $0,1,10,20,40$ and $50 \mu \mathrm{mol} / \mathrm{L}$ of TCBQ and TKO mouse ES cells that were treated with 0 and $40 \mu \mathrm{mol} / \mathrm{L}$ of TCBQ; (b) TCBQ-stimulated dose-dependent formation of $5 \mathrm{hmC}$ in a Tet-mediated manner in mouse ES cells. The enlarged inset showed the $5 \mathrm{hmC}$ levels for TKO mouse ES cells; (d) $5 \mathrm{mC}$ levels were not affected by TCBQ treatment in mouse ES cells. Two-tailed and unpaired student's t-test was performed to assess the statistical significance. " $p<0.05$; ${ }^{* *} p<0.01 ;{ }^{* * *} p<0.001 ; \mathrm{ns}$ denotes no statistical significance. The experiments were conducted three times, and the error bars are the mean $\pm \mathrm{SD}$. $5 \mathrm{hmC}$ : 5-hydroxymethylcytosine; UHPLC-MS/MS: ultra-high performance liquid chromatography-triple quadrupole mass spectrometry; TCBQ: tetrachloro-1,4-benzoquinone.

Annexin-V FITC/PI double staining assay was performed to identify apoptotic cells. The proportion of apoptotic cells was assessed by flow cytometry.

Through the flow cytometry analysis, the representative flow plots were obtained. As shown in Fig. 2a, normal cells appeared in Q3 (Annexin $-\mathrm{V}^{-} / \mathrm{PI}^{-}$), early apoptotic cells appeared in Q4 (Annexin- $\left.\mathrm{V}^{+} / \mathrm{PI}^{-}\right)$, and late apoptotic cells appeared in Q2 (Annexin $-\mathrm{V}^{+} / \mathrm{PI}^{+}$). The total amount of apoptotic cells was the sum of early and late apoptotic cells (Q2 + Q4). 

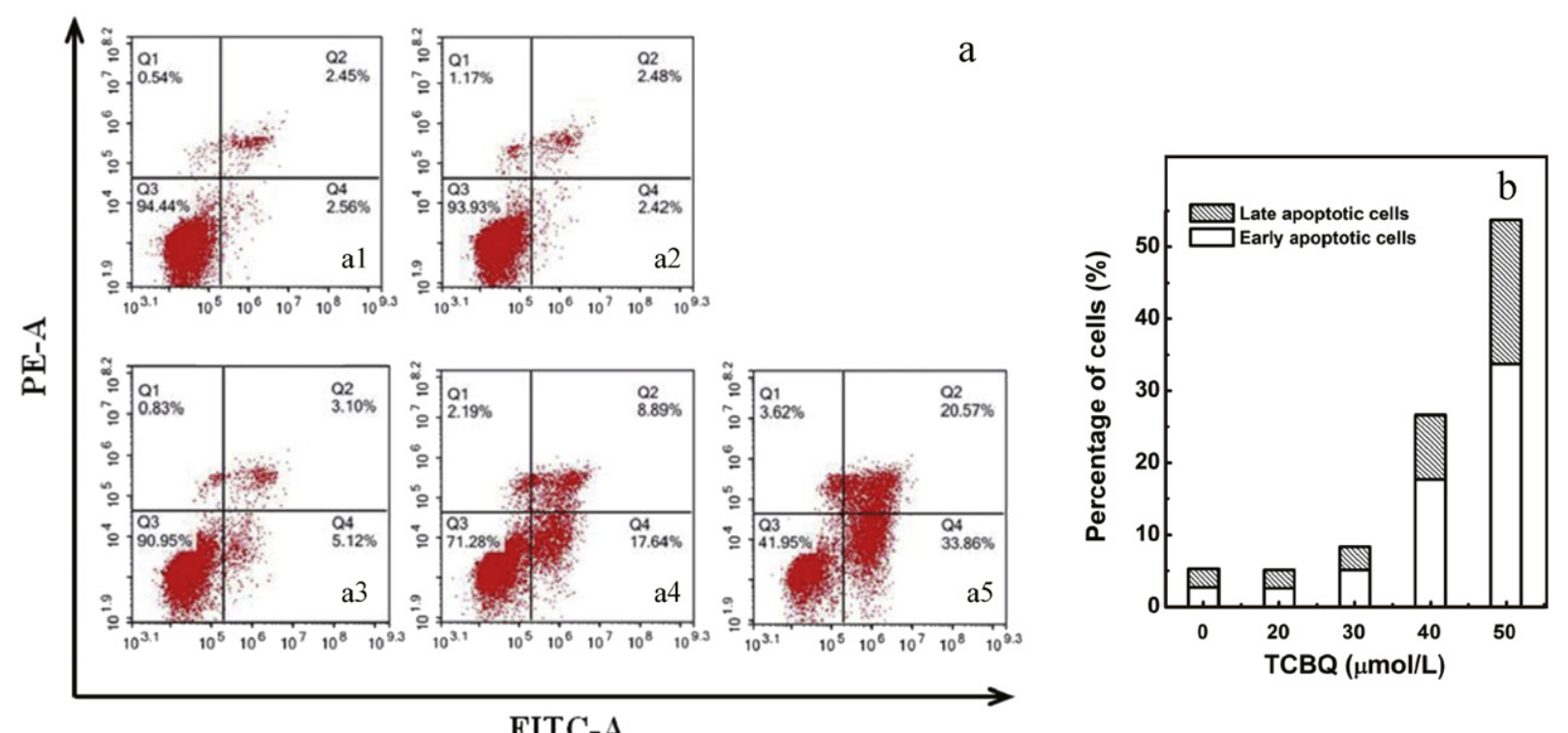

Fig. 2 - TCBQ-induced dose-dependent increase of apoptotic cells in mouse ES cells. (a) Flow cytometric analysis of WT mouse ES cells that were treated with $0,20,30,40$ and $50 \mu \mathrm{mol} / \mathrm{L}$ TCBQ for $24 \mathrm{hr}$ (a1-a5); (b) Increase in the percentage of early apoptotic cells and late apoptotic cells with the increase in TCBQ. WT: wild-type; ES: embryonic stem cell.

By flow cytometry analysis, we found that the increase in the concentration of TCBQ resulted in a remarkable decrease in the number of normal cells, whereas both the percentage of early apoptotic cells and late apoptotic cells significantly increased (Fig. 2). The ratio of normal cells in the control group was $94.4 \%$ (Fig. 2a1). When the cells were treated with $20 \mu \mathrm{mol} / \mathrm{L}$ of TCBQ there was almost no change in the ratio of normal cells compared with the control group (Fig. 2a2). Lower concentrations of TCBQ ( 1 and $10 \mu \mathrm{mol} / \mathrm{L}$ ) were also examined, and the data were not shown because no difference with the untreated group was observed. By augmentation of the concentration of TCBQ to $30 \mu \mathrm{mol} / \mathrm{L}$, the percentage of normal cells decreased by $3.5 \%$ compared to the untreated group (Fig. 2a3). When the cells were exposed to $40 \mu \mathrm{mol} / \mathrm{L}$ of TCBQ, both percentages of early apoptotic cells (from $2.6 \%$ to $17.6 \%$ ) and late apoptotic cells (from $2.5 \%$ to $9.0 \%$ ) significantly increased relative to the untreated group (Fig. 2a4). Obviously, the total percentage of apoptotic cells also increased. The addition of $50 \mu \mathrm{mol} / \mathrm{L}$ of TCBQ caused a more prominent increase in the number of apoptotic cells compared to the addition of $40 \mu \mathrm{mol} / \mathrm{L}$ of TCBQ. The ratio of early apoptotic and late apoptotic cells increased from $2.6 \%$ to $33.9 \%$ and from $2.5 \%$ to $20.6 \%$ for $50 \mu \mathrm{mol} / \mathrm{L}$ TCBQ, respectively (Fig. 2a5). These results indicate that TCBQ induces a dose-dependent increase in both the numbers of early apoptotic cells and late apoptotic cells. Further analysis suggested that early apoptotic cells accounted for a higher proportion in the total number of apoptotic cells (Fig. 2b).

\subsection{Roles of Tet in TCBQ-induced mouse ES cell apoptosis}

According to the data described above TCBQ can promote the dose-dependent increase in $5 \mathrm{hmC}$ in a Tet-dependent manner in mouse ES cells. In addition, we have confirmed that the amount of apoptotic cells increases with the increase in TCBQ concentrations. We further investigated whether Tet enzymes are pertinent to TCBQ-induced cell apoptosis. To confirm the effect of Tet enzymes on TCBQ-induced cell apoptosis, we treated mouse Tet1/Tet2/Tet3 triple knock-out (TKO) ES cells using $0-50 \mu \mathrm{mol} / \mathrm{L}$ of TCBQ and compared the percentage of apoptotic cells with that of wild-type (WT) mouse ES cells.

By flow cytometry analysis, we found that without the TCBQ treatment, the WT and TKO mouse ES cells had notably same ratios of normal cells, which was $94.4 \%$ (Fig. 3a1 and a1'). When the cells were treated with $20 \mu \mathrm{mol} / \mathrm{L}$ of TCBQ there was no significant increase in the number of apoptotic cells in WT and TKO mouse ES cells (Fig. 3a2 and a2'). Further increases in the TCBQ level to $30 \mu \mathrm{mol} / \mathrm{L}$ resulted in a minor increase in both early and late apoptosis regardless of whether the Tet enzymes were knocked out. The proportion of early apoptotic cells increased from $2.6 \%$ to $5.1 \%$ in WT and from $1.2 \%$ to $6.4 \%$ in TKO mouse ES cells; simultaneously, late apoptotic cells increased from $2.5 \%$ to $3.1 \%$ in WT and from $3.6 \%$ to $6.4 \%$ in TKO mouse ES cells (Fig. $3 a 3$ and a3'). Both the percentages of early apoptotic cells and late apoptotic cells were slightly higher in TKO than in WT mouse ES cells, and the sum of apoptotic cells in TKO (12.9\%) was $4.6 \%$ higher than that in WT mouse ES cells (8.3\%). Therefore, the Tet triple knock-out caused a slight increase in the percentage of apoptotic cells when the cells were exposed to $30 \mu \mathrm{mol} / \mathrm{L}$ TCBQ. In other words, Tet enzymes suppresses the apoptosis in the presence of $30 \mu \mathrm{mol} / \mathrm{L}$ TCBQ. When we increased the TCBQ concentration to 40 and $50 \mu \mathrm{mol} / \mathrm{L}$, the total percentage of apoptotic cells was almost identical in TKO and WT mouse ES cells (Fig. 3b). However, further analysis revealed that the ratio of early apoptotic cells was significantly higher in WT than that in TKO mouse ES cells, whereas there were fewer late apoptotic cells in WT than in TKO mouse ES cells (Figs. $3 a 4, a 4^{\prime}$ and $\left.a 5, a 5^{\prime}\right)$. The detailed data were shown in Table 1. 


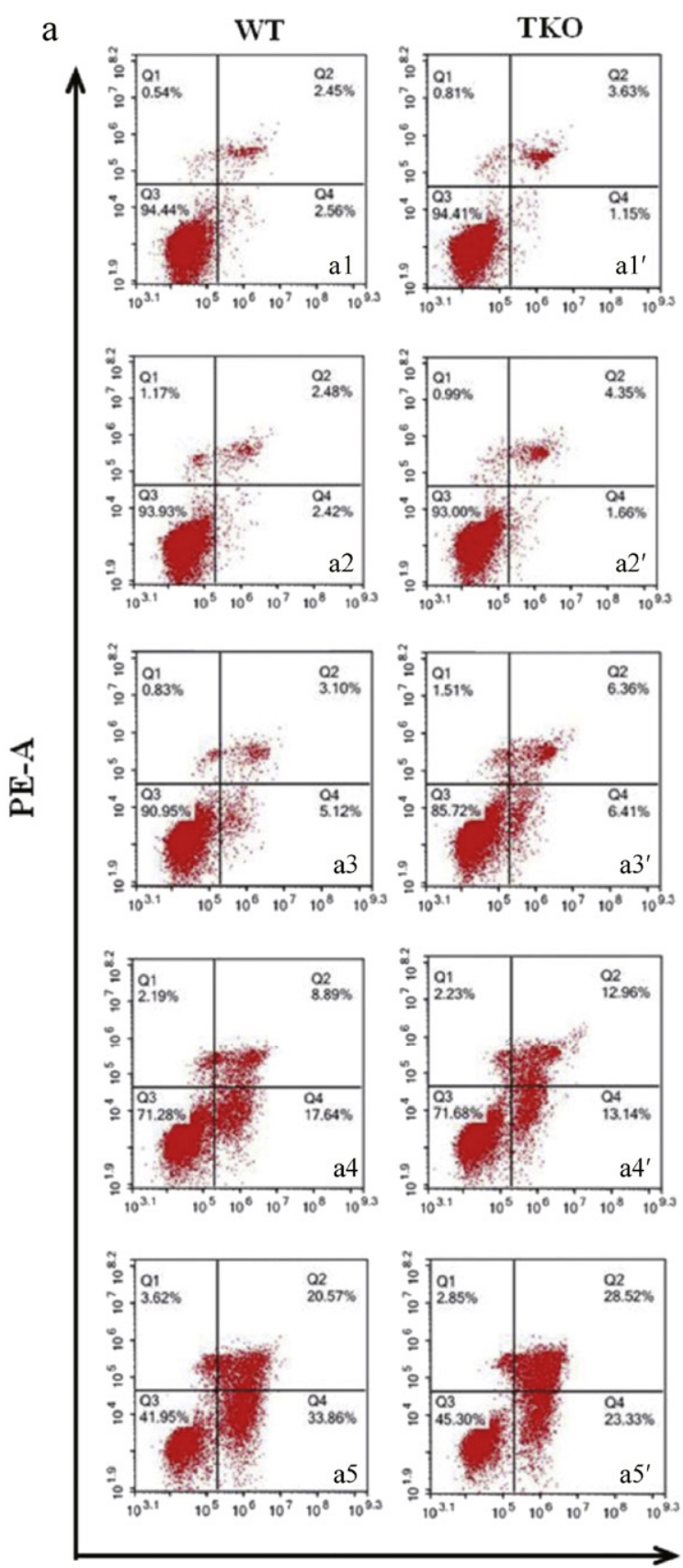

FITC-A

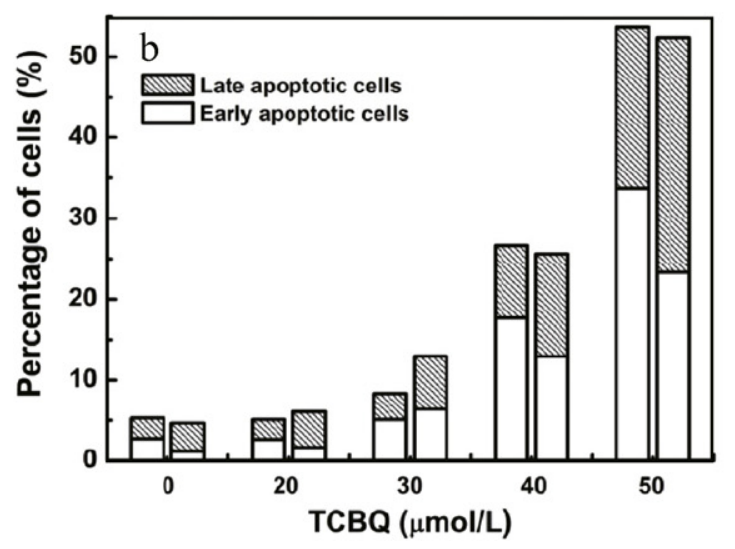

These results suggest that the Tet knock-out did not alter the proportion of total apoptotic cells. However, it induced more cells into late-stage apoptosis from early stage apoptosis. In other words, Tet enzymes partially inhibited early apoptotic cells from progressing to late apoptosis in the presence of 40 and $50 \mu \mathrm{mol} / \mathrm{L}$ TCBQ. Collectively, Tet enzymes slightly repressed apoptosis at a relative low concentration of TCBQ $(30 \mu \mathrm{mol} / \mathrm{L})$, whereas at higher concentrations $(40$ and $50 \mu \mathrm{mol} / \mathrm{L}$ ), Tet partially prevented the cells to enter the late stage of apoptosis from the early stage, that is, Tet dioxygenases are implicated in TCBQ-induced apoptosis in mouse ES cells.

As the dominant form of programmed cell death, apoptosis is characterized by cell shrinkage, hypercondensation of chromatin, cleavage of chromosomes into nucleosomes, blebbing of the plasma membrane, and formation of apoptotic bodies by packaging cellular contents into membrane-enclosed vesicles (Shi, 2001). Apoptosis plays an important role in cellular homeostasis (Liao et al., 2016). Cell apoptosis has two stages: early stage apoptosis and late-stage apoptosis. During early stage of apoptosis, the plasma membrane is intact, and membrane phosphatidylserine (PS) is translocated from the inner region to the cell surface (Koopman et al., 1994). Annexin V has a high affinity for PS; thus, early apoptotic cells can be identified by a fluorescent conjugate (FITC) of Annexin $\mathrm{V}$ (Annexin $\mathrm{V}^{+} / \mathrm{PI}^{-}$) (Koopman et al., 1994). When the cells enter the late stage of apoptosis, the membrane integrity is disrupted, which allows propidium iodide (PI) to enter the nucleus, intercalate into DNA, and cause red fluorescence (Annexin $\mathrm{V}^{+} / \mathrm{PI}^{+}$) (Darzynkiewicz et al., 1992).

Our recent study demonstrated that the Tet-dependent increase of $5 \mathrm{hmC}$ significantly changes the gene expression in 3414 genes that are involved in the protein catabolic process, cell localization, RNA processing procedure and apoptosis signaling pathway (Zhao et al., 2014). We speculate that all of the effects of Tet dioxygenases on TCBQ-induced apoptosis may be attributed to the change in apoptosis-related gene expression because of the enhanced Tet activity through TCBQ. On the basis of the widespread use of PCP, its metabolite TCBQ also ubiquitously exists in our eco-environment. Our work offers new insights into the cytotoxicity research by taking advantage of more sensitive embryonic stem cells. In addition, we for the first time show the linkage of the TCBQ-induced apoptosis with the epigenetics. Of note, TCBQ is a representative of halogenated quinones. Some halogenated quinones have even been detected in drinking water (Qin et al., 2010). Therefore, the observed effects of TCBQ are potentially applicable to other halogenated quinones.

Fig. 3 - Effect of Tet enzymes on TCBQ-induced cell apoptosis, which was measured using flow cytometry. (a) Representative flow plots of WT and TKO mouse ES cells that were treated with TCBQ. The plots of a1-a5 and a1'-a5' correspond to the treatment of $0,20,30,40$ and $50 \mu \mathrm{mol} / \mathrm{L}$ of TCBQ, where a and $\mathrm{a}^{\prime}$ denote WT and TKO mouse ES cells, respectively; (b) The apoptotic percentage of WT (left bar) and TKO (right bar) mouse ES cells caused by TCBQ. TKO: triple-knockout. 
Table 1 - The percentage of apoptotic cells induced by a series of TCBQ concentrations in WT and TKO mouse ES cells.

WT mouse ES cells
Early apoptotic cells

$(\%)$
Late apoptotic cells

(\%)
TKO mouse ES cells

\begin{tabular}{cccccc}
\multirow{2}{*}{$\begin{array}{c}\mathrm{TCBQ} \\
(\mu \mathrm{mol} / \mathrm{L})\end{array}$} & Average & $\mathrm{SD}$ & & \multicolumn{2}{c}{$(\%)$} \\
\cline { 2 - 3 } \cline { 5 - 6 } & 2.7 & 0.2 & & Average & $\mathrm{S}$ \\
\hline 0 & 2.6 & 0.2 & 2.5 & 0.1 \\
20 & 5.1 & 0.3 & 3.2 & 0.2 \\
30 & 17.7 & 0.2 & 9.0 & 0.2 \\
40 & 33.7 & 0.4 & 20.0 & 0.8 \\
50 & & & &
\end{tabular}

\begin{tabular}{ccccc}
\hline \multirow{2}{*}{$\begin{array}{c}\text { Early apoptotic cells } \\
(\%)\end{array}$} & & \multicolumn{2}{c}{$\begin{array}{c}\text { Late apoptotic cells } \\
(\%)\end{array}$} \\
\cline { 5 - 6 } Average & SD & & Average & SD \\
\hline 1.1 & 0.1 & & 3.5 & 0.1 \\
1.6 & 0.1 & & 4.4 & 0.2 \\
6.3 & 0.3 & & 6.6 & 0.3 \\
12.9 & 0.3 & & 12.7 & 0.6 \\
23.3 & 1.1 & & 29.0 & 0.5 \\
\hline
\end{tabular}

\section{Conclusions}

In this study, we demonstrated the effects of TCBQ on apoptosis of mouse ES cells. We initially tested the change in the $5 \mathrm{hmC}$ level induced by TCBQ and found that TCBQ promoted a concentration-dependent generation of $5 \mathrm{hmC}$ in a Tetdependent manner. By apoptosis analysis, we showed that TCBQ induced a dose-dependent increase in apoptotic cells and there were more early apoptotic cells than late apoptotic cells. An investigation on the role of Tet in TCBQ-induced apoptosis shows that Tet dioxygenases suppresses both early and late apoptosis at a relatively low concentration of TCBQ $(30 \mu \mathrm{mol} / \mathrm{L})$, but at higher concentrations (40 and $50 \mu \mathrm{mol} / \mathrm{L}$ ), the Tet enzymes have almost no effect on the total percentage of apoptotic cells. However, the knockout of three Tet dioxygenases induces more cells to enter the late stage of apoptosis. Thus, Tet plays a critical role in modulating cell apoptosis. Based on these studies, we know that TCBQ can trigger mouse ES cell apoptosis, which is linked with Tet dioxygenases.

\section{Acknowledgment}

This work was supported by the National Natural Science Foundation of China (Nos. 21327006, 21435008, 21321004), and the Strategic Priority Research Program of the Chinese Academy of Sciences (No. XDB14030200).

\section{R E F E R E N C E S}

Angelucci, D.M., Tomei, M.C., 2015. Pentachlorophenol aerobic removal in a sequential reactor: start-up procedure and kinetic study. Environ. Technol. 36, 327-335.

Bird, A., 2002. DNA methylation patterns and epigenetic memory. Genes Dev. 16, 6-21.

Darzynkiewicz, Z., Bruno, S., Del Bino, G., Gorczyca, W., Hotz, M.A., Lassota, P., et al., 1992. Features of apoptotic cells measured by flow cytometry. Cytometry 13, 795-808.

Deaton, A.M., Bird, A., 2011. CpG islands and the regulation of transcription. Genes Dev. 25, 1010-1022.

Faiola, F., Yin, N., Yao, X., Jiang, G., 2015. The rise of stem cell toxicology. Environ. Sci. Technol. 49, 5847-5848.

Hattemer-Frey, H.A., Travis, C.C., 1989. Pentachlorophenol: environmental partitioning and human exposure. Arch. Environ. Contam. Toxicol. 18, 482-489.
He, Y.F., Li, B.Z., Li, Z., Liu, P., Wang, Y., Tang, Q., et al., 2011. Tet-mediated formation of 5-carboxylcytosine and its excision by TDG in mammalian DNA. Science 333, 1303-1307.

Hu, L., Su, C., Song, X., Shi, Q., Fu, J., Xia, X., et al., 2015. Tetrachlorobenzoquinone triggers the cleavage of bid and promotes the cross-talk of extrinsic and intrinsic apoptotic signalings in pheochromocytoma (PC) 12 cells. Neurotoxicology 49, 149-157.

IARC, 1991. Pentachlorophenol. IARC monographs on the evaluation of carcinogenic risks to humans: occupational exposures in insecticide application, and some pesticides. Monogr. Eval. Carcinog. Risk Hum. 53, 371-402.

Koopman, G., Reutelingsperger, C.P., Kuijten, G.A., Keehnen, R.M., Pals, S.T., van Oers, M.H., 1994. Annexin V for flow cytometric detection of phosphatidylserine expression on B cells undergoing apoptosis. Blood 84, 1415-1420.

Li, E., Zhang, Y., 2014. DNA methylation in mammals. Cold Spring Harb. Perspect. Biol. 6, a019133.

Li, J.H., Fu, K.Z., Vemula, S., Le, X.C., Li, X.-F., 2015. Studying developmental neurotoxic effects of bisphenol A (BPA) using embryonic stem cells. J. Environ. Sci. 36, 173-177. http://dx.doi. org/10.1016/j.jes.2015.08.002.

Liao, W.Z., Lai, T., Chen, L.Y., Fu, J.N., Sreenivasan, S.T., Yu, Z.Q., et al., 2016. Synthesis and characterization of a walnut peptides-zinc complex and its antiproliferative activity against human breast carcinoma cells through the induction of apoptosis. J. Agric. Food Chem. 64, 1509-1519.

Lin, P.H., Nakamura, J., Yamaguchi, S., Upton, P.B., La, D.K., Swenberg, J.A., 2001. Oxidative damage and direct adducts in calf thymus DNA induced by the pentachlorophenol metabolites, tetrachlorohydroquinone and tetrachloro-1,4-benzoquinone. Carcinogenesis 22, 627-634.

Lin, J.R., Qin, H.H., Wu, W.Y., He, S.J., Xu, J.H., 2014. Vitamin C protects against UV irradiation-induced apoptosis through reactivating silenced tumor suppressor genes p21 and p16 in a Tet-dependent DNA demethylation manner in human skin cancer cells. Cancer Biother. Radiopharm. 29, 257-264.

Maiti, A., Drohat, A.C., 2011. Thymine DNA glycosylase can rapidly excise 5-formylcytosine and 5-carboxylcytosine: potential implications for active demethylation of CpG sites. J. Biol. Chem. 286, 35334-35338.

Qin, F., Zhao, Y.Y., Zhao, Y., Boyd, J.M., Zhou, W., Li, X.F., 2010. A toxic disinfection by-product, 2, 6-dichloro-1, 4-benzoquinone, identified in drinking water. Agnew. Chem. Int. Ed. 49, 790-792.

Shi, Y., 2001. A structural view of mitochondria-mediated apoptosis. Nat. Struct. Biol. 8, 394-401.

Tahiliani, M., Koh, K.P., Shen, Y., Pastor, W.A., Bandukwala, H., Brudno, Y., et al., 2009. Conversion of 5-methylcytosine to 5-hydroxymethylcytosine in mammalian DNA by MLL partner TET1. Science 324, 930-935. 
Wu, S.C., Zhang, Y., 2010. Active DNA demethylation: many roads lead to Rome. Nat. Rev. Mol. Cell Biol. 11, 607-620.

Wu, H., Zhang, Y., 2011. Mechanisms and functions of Tet protein-mediated 5-methylcytosine oxidation. Genes Dev. 25, 2436-2452.

Yin, R., Mao, S.Q., Zhao, B., Chong, Z., Yang, Y., Zhao, C., et al., 2013a. Ascorbic acid enhances Tet-mediated 5-methylcytosine oxidation and promotes DNA demethylation in mammals. J. Am. Chem. Soc. 135, 10396-10403.

Yin, R., Zhang, D., Song, Y., Zhu, B.Z., Wang, H., 2013b. Potent DNA damage by polyhalogenated quinones and $\mathrm{H}_{2} \mathrm{O}_{2}$ via a metal-independent and intercalation-enhanced oxidation mechanism. Sci. Rep. 3, 1269.

Yin, N., Yao, X., Qin, Z., Wang, Y.L., Faiola, F., 2015. Assessment of Bisphenol A (BPA) neurotoxicity in vitro with mouse embryonic stem cells. J. Environ. Sci. 36, 181-187.
Zhao, B.L., Yang, Y., Wang, X.L., Chong, Z.C., Yin, R.C., Song, S.H., et al., 2014. Redox-active quinones induces genome-wide DNA methylation changes by an iron-mediated and Tet-dependent mechanism. Nucleic Acids Res. 42, 31593-31605.

Zheng, W., Yu, H., Wang, X., Qu, W., 2012. Systematic review of pentachlorophenol occurrence in the environment and in humans in China: not a negligible health risk due to the re-emergence of schistosomiasis. Environ. Int. 42, 105-116.

Zhu, B.Z., Shan, G.Q., 2009. Potential mechanism for pentachlorophenol-induced carcinogenicity: a novel mechanism for metal-independent production of hydroxyl radicals. Chem. Res. Toxicol. 22, 969-977. 